\title{
THE 42nd INTERNATIONAL S.B. STECHKIN'S WORKSHOP-CONFERENCE ON FUNCTION THEORY
}

\author{
Vitalii V. Arestov ${ }^{\dagger}$ and Vitalii I. Berdyshev ${ }^{\dagger \dagger}$ \\ Krasovskii Institute of Mathematics and Mechanics, \\ Ural Branch of the Russian Academy of Sciences and \\ Ural Federal University, Ekaterinburg, Russia \\ †vitalii.arestov@urfu.ru, ${ }^{\dagger}$ bvi@imm.uran.ru
}

\begin{abstract}
The paper is devoted to the description of the history and results of the 42nd International S.B. Stechkin's Workshop on function theory, held in August 2017 in the Ilmen Nature Reserve near the town of Miass, Chelyabinsk region.
\end{abstract}

Key words: The 42nd International S.B. Stechkin's Workshop on function theory.

From the sixties of the XX century onwards, at the Institute of Mathematics and Mechanics of the Ural Branch of the Russian Academy of Sciences and at A.M. Gor'kii Ural State University, a powerful scientific school on function theory has been formed, which works intensively till nowadays. The founder of this school was Professor S.B. Stechkin - the organizer of the Institute and the professor of the University, who passed away in 1995. A number of leading world experts in the theory of functions and operators have grown up in this school: academicians V.I. Berdyshev and S.V. Konyagin, corresponding member of the Russian Academy of Sciences Yu.N. Subbotin, doctors of science, professors A.R. Alimov, N.Yu. Antonov, V.V. Arestov, A.G. Babenko, V.M. Badkov, N.I. Chernykh, V.I. Ivanov, L.V. Taikov, S.A. Telyakovskii, I.G. Tsar'kov, A.Yu. Shadrin, V.T. Shevaldin, A.S. Shvedov, V.A. Yudin, and dozens of candidates of science. Many of them at present have positions both in the Institute and in the University. The scientific school has a high reputation in the world. With the purpose of discussing research results and ways of further scientific studies, in the beginning of the 1970th, annual summer scientific workshopsconferences on function theory and approximation theory were organized. The organizer and the all-time leader of most of them was Professor S.B. Stechkin, this tradition continues to the present. During these workshops-conferences, not only new scientific results are presented but also open problems of function theory and approximation theory and possible approaches to their solution as well as forthcoming dissertations are discussed. The duration of these workshops allow their participants to deliver as complete presentation of their research as they reasonably need. Talks are accompanied with numerous revealing questions and remarks of other participants, which are traditionally welcome. The atmosphere is friendly and homelike. Talks are usually given under the open-air on a clearing in the wood. In addition to participants from Ekaterinburg (from Institute of Mathematics and Mechanics of the Ural Branch of the Russian Academy of Sciences and from Ural Federal University), workshop-conferences traditionally accept leading scientists and their students from Moscow (form Moscow State University, V.A. Steklov Mathematical Institute, and other institutions), Novosibirsk, Ozersk, Saratov, Tula, and from other cities in Russia and abroad (Azerbaijan, China, Kazakhstan, Ukrain, and others). A distinctive feature of Workshop-2017 was a considerable number of new young participants which inspires hope for preserving the traditions and inimitable spirit of Stechkin's School. Detailed historical reviews on past workshops can be found in $[1-3]$. 


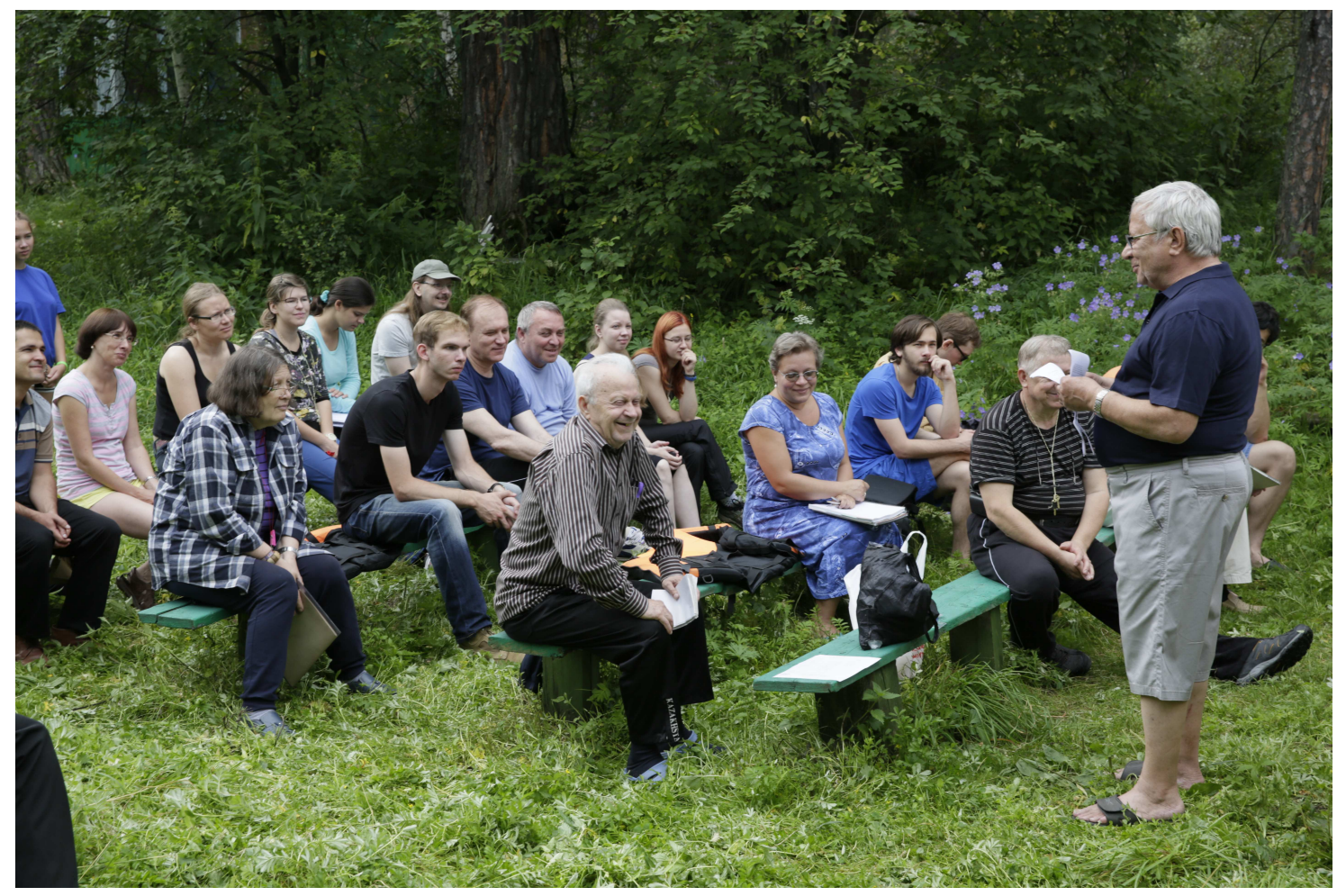

Figure 1. The opening ceremony of S.B. Stechkin's Workshop (August 2, 2017)

The 42nd International S.B. Stechkin's Workshop-Conference on function theory was held on August 1-10, 2017. It was organized by the Krasovskii Institute of Mathematics and Mechanics of the Ural Branch of the Russian Academy of Sciences and Ural Federal University (Ekaterinburg). The conference venue was the shore of Ilmen lake in the Ilmen Nature Reserve near the city of Miass, Chelyabinsk region.

\section{Organizing Committee}

Chairmen: V.V. Arestov and V.I. Berdyshev (Ekaterinburg, Russia)

Members: A.G. Babenko (Ekaterinburg, Russia), E.E. Berdysheva (Giessen, Germany), N.I. Chernykh (Ekaterinburg, Russia), P.Yu. Glazyrina (Ekaterinburg, Russia), N.A.Il'yasov (Baku, Azerbaijan), S.V. Konyagin (Moscow, Russia), Szilárd Révész (Budapest, Hungary), Yu.N. Subbotin (Ekaterinburg, Russia), M.Sh. Shabozov (Dushanbe, Tajikistan), S.I. Novikov (Ekaterinburg, Russia).

Programming Committee: V.V. Arestov (chairman), N.Yu. Antonov, and M.V. Deikalova (Ekaterinburg, Russia).

The Workshop-Conference was attended by 35 scientists from Moscow, Ekaterinburg, and former Soviet republics: Kazakhstan, Tadjikistan, Turkmenistan, and Ukraine, including one academician of the Russian Academy of Sciences, 8 doctors of science, 14 candidates of science, 9 students and undergraduates, and 3 post-graduate students. They delivered 34 research talks on basic topics of modern function theory and approximation theory, and on applications of approximation methods to solving problems in other areas of mathematics:

- general problems of function theory;

- best approximation of functions and operators; 
- extremal problems of function theory and approximation theory;

- modern approximation methods: splines, wavelets, and their application to problems of data compression and medicine;

- problems of navigation by geodesic fields;

- geometric problems of approximation theory;

- numerical analysis.

Several selected papers presented at the Workshop are published in this issue of the journal.

\section{REFERENCES}

1. Berdyshev V.I. Stechkin's workshop - what is it? // East J. Approx., 1996. Vol. 2, no. 2. P. 135-142.

2. Berdyshev V.I. Chronology of S.B. Stechkin's Workshops 1971-2006 // Proc. Internat. Stechkin Summer School on Function Theory (Izd. Tul'sk. Gos. Univ., Tula, 2007), pp. 7-14. [in Russian]

3. Berdyshev V.I., Arestov V.V., and Shabozov M.Sh. S.B. Stechkin's Workshop: Historical note // Proc. Internat. Summer Math. Stechkin School-Conference on Function Theory. Dushanbe: Publishing House of OOO "Ofset", 2016. P. 6-10. [in Russian] 